\title{
Dynamics modeling and analysis of feed drive system for a frame saw machine considering time-varying load
}

\author{
Depeng Sun ${ }^{1,2,3}$ and Jinsheng Zhang ${ }^{1,2,3, *}$ \\ ${ }^{1}$ School of Mechanical Engineering, Shandong University, PR China \\ ${ }^{2}$ Key Laboratory of High-efficiency Clean Mechanical Manufacture of Ministry of Education \\ ${ }^{3}$ Research Centre for Stone Engineering, Shandong Province, Ji'nan 250061, PR China
}

Received: 9 September 2020 / Accepted: 23 February 2021

\begin{abstract}
Frame saw machine is one of machine tools that is used to process dimension stone. The velocity fluctuation of traditional feed drive system (FDS) lead to excessive wear of diamond particles. The dynamic performance of the FDS has time-varying characteristics during the processing of stone with a large material removal rate. In this paper, a novel FDS was proposed. Firstly, the dynamic modeling of FDS was set up on account of lumped parameter method (LPM). Then the speed of the new FDS was compared with that of the traditional FDS. Finally, the frequency response characteristics of the system were solved by Lagrange and state space method. Results showed that the new FDS has a faster response feed and less velocity fluctuation. The natural frequency and the amplitude of acceleration increase with decreasing load. With the time-varying load, the range of the second-order natural frequency increased by $50 \mathrm{~Hz}$, which was larger than that of the first-order. The modal test verified that the first two natural frequencies of the saw blade are within the range of the natural frequencies of FDS. The proposed FDS can guide for design, reduce the wear of diamond, and improve processing quality.
\end{abstract}

Keywords: Feed drive system / dynamics modeling / frequency response analysis / time-varying load

\section{Introduction}

Since granite, the Mohs hardness scale is 6-7, slab processing is the difficult problem all over the word [1]. The three-phase asynchronous motor is widely used as the driving source in the FDS of frame saw. However, the transmission chain is complex, including the slender transmission shaft, chain, etc. Thereby, the traditional FDS has obvious weaknesses: small stiffness, weak speed controllability, and hysteresis nonlinearity. The unstable feed speed leads to the excessive cutting force, the decrease of dynamic holding chip space and the increment of diamond wear [2]. Hence, the stable feed speed is needed for grinding stone with diamond as cutting tool. In this study, a novel servo feed mechanism in the light of a rotary-nut lead screw was proposed, which possessed higher stiffness, more stable feed speed and dynamic response. Further, the vibration of nut-driven system is small than that of screw driven feed system.

The quality of slab is evaluated using the flatness, which is an acceptable geometrical accuracies of $1.5 \mathrm{~mm} / \mathrm{m}$.

\footnotetext{
* e-mail: zhangjs@sdu.edu.cn
}

The flatness mainly depends on the dynamic characteristic of the frame saw machine. Therefore, a significant way of improving flatness is to analyze the dynamic behavior of the frame saw machine. Dynamic characteristic of the FDS affects the machining performance [3]. The dynamic characteristic of FDS can be predicted by the dynamic model. Currently, there are two drive ways of FDS for machine tools: one is linear motor, the other is rotary servo motor and ball screw [4].

Finite element model, LPM and hybrid model and are the three main dynamic models of the ball screw FDS. The ball screw FDS has been studied by many researchers. Mu [5] discussed the influences of table position and workpiece mass on the first-three axial modes of the nut-driven system, by establishing a dynamic model using LPM. Yu and Feng [6] utilized the LMP to set up dynamics modeling for the differential system. The preload of nut, rigidity and mass of table affect the frequency-response characteristics were investigated. Wang and Feng [7] investigated the merits of nut-drive system. Compared the screw drive system with nut drive system by dynamics models. The results showed that the mechanism has faster responsiveness. Position error is smaller than screw drive. Zhang and Zhao [8] presented a dynamic model considering the 


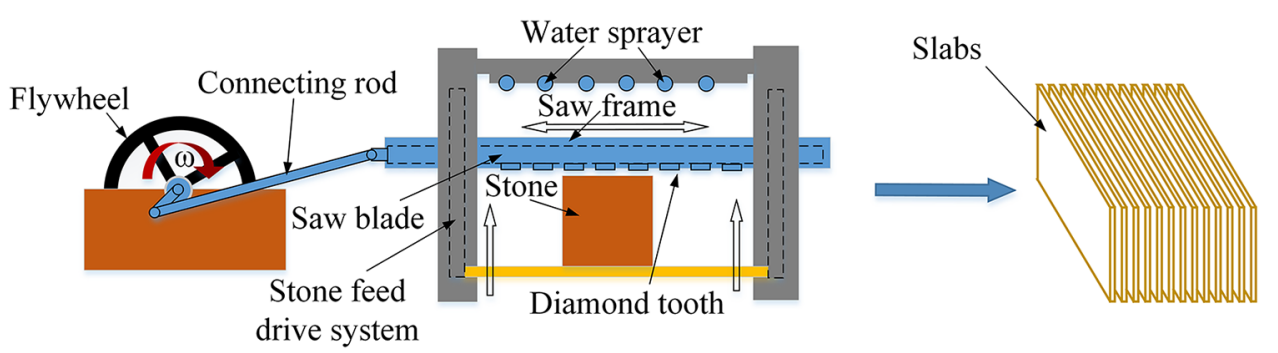

Fig. 1. Diagram of the frame saw machine for cutting stone.

pre-stretching of lead screw that screw was divided into three parts, and the model was established using the LPM. Firstly, the system natural frequency was analyzed. Secondly, the frequency response was measured by designed auxiliary clamping device. Li et al. [9] studied the effect of the additional torque which increased the axial thrust on the preload of screw, and improved the lumped parameter model that was improved. What's more, the vibration tests were performed to measure the first resonant frequency for system to verify the model. Henke et al. [10] established a distributed parameter model of FDS using Ritz series discretization and discussed the frequency responses of ball screw drive system with changing stiffness and inertia. This model was fitted well for the control design thanks to the ball screw, which has been treated as a flexible element. Lee et al. [11] presented a dynamic model of FDS using finite element method considering the machine structure and control system, and the workpiece surface quality was predicted using this model. Du et al. [12] analyzed that load disturbance affects the deformation of raceway and ball. The dynamic characteristics of system was changed.

The researchers analyzed from different perspectives such as vibration, frequency response characteristics and driving methods. The literature reviews show that the dynamic modeling of FDS placed horizontally have been researched. There is a lack in the low-speed and heavy load FDS of frame saw machine. Previous studies mostly focused on the traditional way, but did not study the new FDS. The current research on stone processing mostly focuses on sawability [13] and diamond wear. The dynamic characteristics of FDS affect the diamond wear rate, but it has not been considered. Hence, this paper studies the dynamic characteristics of a new type of heavy-duty FDS.

In this paper, a novel heavy-duty FDS for frame saw machine was proposed. About $25 \%$ of the material is removed during stone processing. Hence, the dynamic characteristics of the feed system are time-varying along with material removal. The dynamic characteristics of the heavy-duty FDS was analyzed considering the timevarying load. Processing pattern of stone and the structure of heavy-duty FDS is introduced in Section 2. The dynamics modeling of FDS is established using LPM in Section 3. The frequency response and velocity fluctuation of FDS are analyzed by numerical simulations in Section 4. Finally, conclusions are in Section 5.

\section{Mechanical model of the stone feed drive system of frame saw machine}

The frame saw machine shown in Figure 1 is widespreadly used in stone processing. The rotation speed of the flywheel can be adjusted from 0 to $90 \mathrm{r} / \mathrm{min}$ that drives the saw frame to swing forward and backward [14,15]. What is more, the saw blades are anchored on the saw frame and cutting stone with diamond saw-teeth. The traditional FDS, including asynchronous motor and chain, leads to unstable feed speed which aggravate the wear of diamond. Hence, alternating force acts on the saw blade resulting in deviation, which ultimately affects the processing quality.

According to the principle of grinding, the fluctuation of feed speed in the process of materials processing will change the maximum deformation chip thickness. The maximum deformation is the change of cutting thickness, which leads to the increase of force on diamond particles and the decrease of dynamic chip holding space, resulting in serious diamond wear. Figure 2 shows the structure of the novel stone FDS. The nut is driven by servo motor rather than fixed. On the one hand, one end of the screw is connected to the platform with bolts instead of rotation. According to the principle of screw drive, the screw is driven by rotatingnut. The platform moves up with the screw. The weight of stone is generally several tons. Hence, the trapezoidal screw, self-locking characteristics, is often used as the transmission component in consideration of the safety of the processing process. Four feed drive systems, synchronized movement, are installed on the four corners of the frame saw to achieve the feed movement of the stone. The FDS mainly realizes one-direction feed movement without considering the influence of reverse error. Meanwhile, the torsional deformation produced by the components has an effect on the feed speed at the initial stage, and almost no effect after reaching the system balance.

\section{Dynamics model of the feed drive system}

The dynamic characteristics of FDS affect the quality of stone processing. The FDS was modeled using LPM in order to investigate dynamic characteristic, as shown in Figure 3.

The trapezoidal screw is arranged vertically as shown in Figure 2. The axial rigidity of the trapezoidal screw may be changed due to the change of position [16]. Moreover, the 
Motor

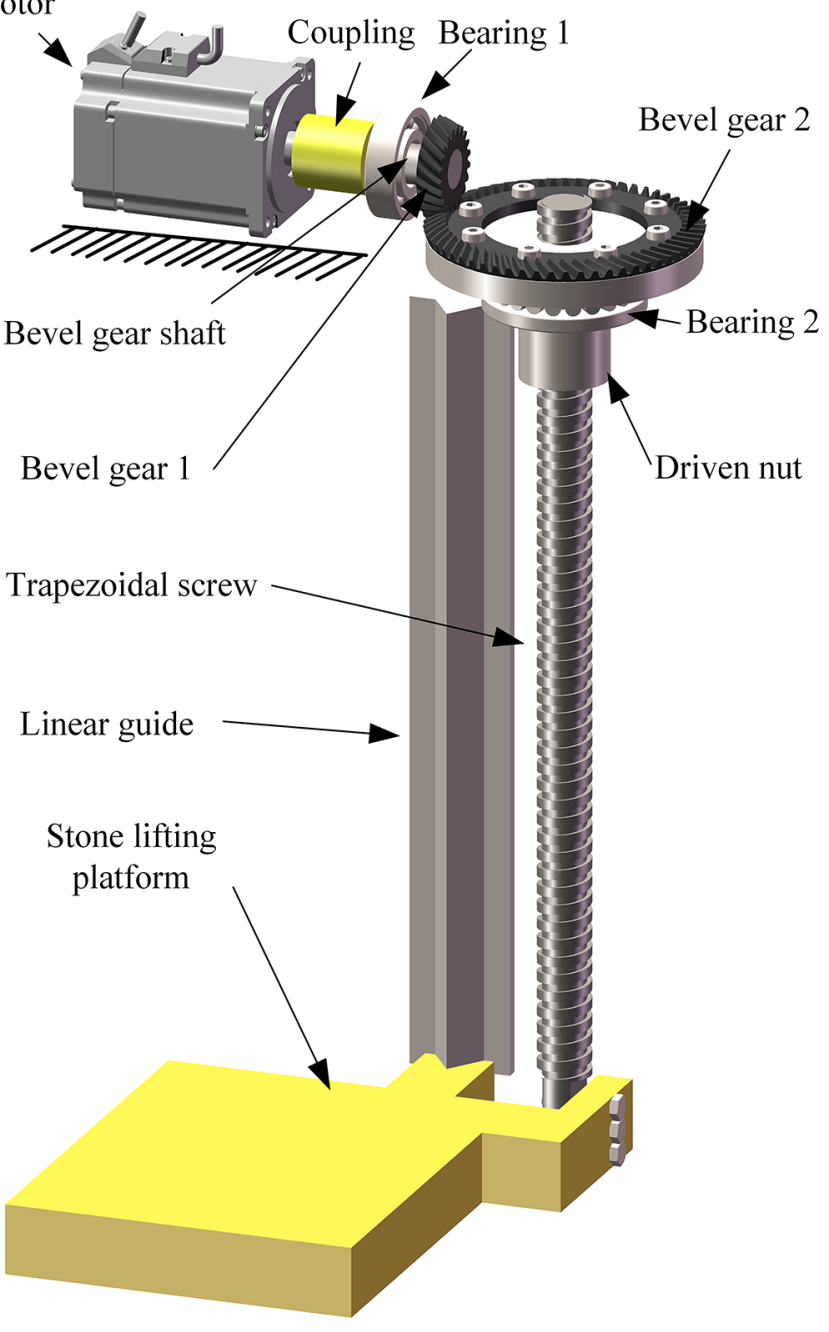

Fig. 2. Mechanical components of FDS.

axial rigidity may be changed with the change of load. Consequently, it affects the positioning accuracy. Axial stiffness of screw is given by

$$
K_{s a}=\frac{A E}{1000 L}
$$

where $A$ is the cross-secctional area, $L$ is the stroke length, $E$ is the elastic modulus, $E=2.06 \times 10^{5} \mathrm{MPa}$.

The torsional stiffness of nut is given as follows:

$$
K_{n t}=\frac{\pi G\left(D_{n}^{4}-d_{n}^{4}\right)}{32 L_{n}}
$$

where $D_{n}, L_{n}$ and $d_{n}$, are diameter, the length of nut, thread diameter, respectively. $G$ is the elastic modulus, $G=8.24$ $\times 10^{4} \mathrm{MPa}$.

The torsional stiffness of the bevel gear shaft is given by

$$
K_{\text {bgs }}=\frac{\pi d^{4} G}{32 L_{s}}
$$

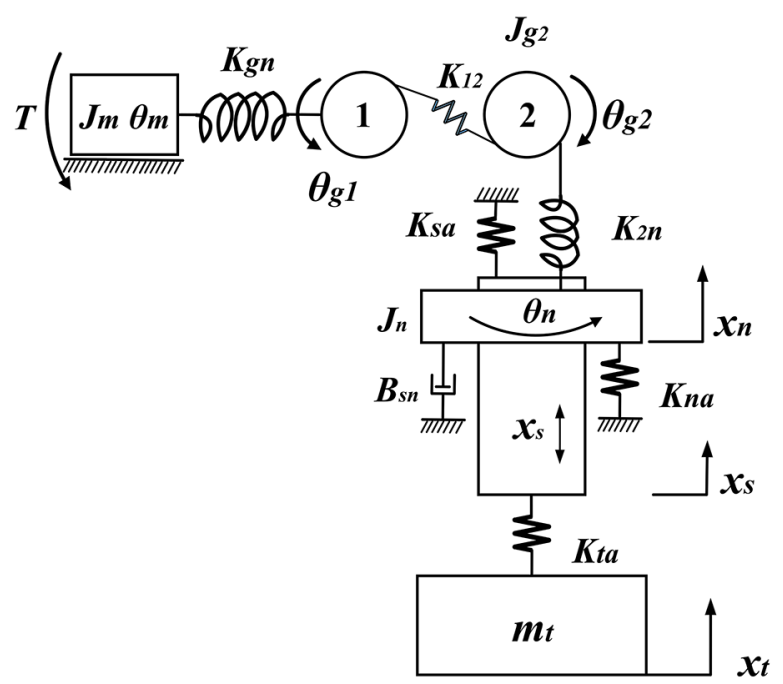

Fig. 3. Schematic for dynamic model of FDS based on LPM.

where $d$ is the diameter, $L_{\mathrm{s}}$ is the length of bevel gear shaft.

Single tooth stiffness of gear, giving

$$
K_{n}=\frac{F_{n}}{b \delta_{n}}
$$

where $F_{n}$ is normal contact force of tooth profile surface, $b$ is tooth width, $\delta_{n}$ is normal deformation of gear teeth.

For the dynamic model of FDS as shown in Figure 3, the synthesis torsional rigidity of coupling and bevel gear shaft in term of the principle of stiffness synthetic, giving

$$
K_{g n}=\left(\frac{1}{K_{c}}+\frac{1}{K_{\text {bgs }}}\right)^{-1}
$$

The meshing stiffness of contact pair of two gears in series coupling [17] can be briefly expressed as

$$
K_{12}=\left(\frac{1}{K_{1}}+\frac{1}{K_{2}}\right)^{-1}
$$

where $K_{1}$ and $K_{2}$ are the single tooth stiffness of bevel gear 1 and bevel gear 2, respectively.

Similarly, synthesis torsional rigidity of nut and gear 2, giving

$$
K_{2 n}=\left(\frac{1}{K_{n t}}+\frac{1}{K_{g t}}\right)^{-1}
$$

Table 1 lists the parameters that were acquired from manufacturers' manuals or prior knowledge used in the modeling. The moment of inertia of mechanical parts was obtained from Solidworks.

As shown in Figure 3, in light of Lagrange energy method [18], the kinetic energy of the FDS is described as

$$
T=\frac{1}{2} J_{m} \dot{\theta}_{m}^{2}+\frac{1}{2} J_{g 1}\left(\frac{\dot{\theta}_{m}+\dot{\theta}_{g 1}}{2}\right)^{2}+\frac{1}{2} J_{g 2}\left(\frac{\dot{\theta}_{g 1}+\dot{\theta}_{g 2}}{2}\right)^{2}
$$

$$
+\frac{1}{2} J_{n}\left(\frac{\dot{\theta}_{g 2}+\dot{\theta}_{n}}{2}\right)^{2}+\frac{1}{2} m_{n} \dot{x}_{n}{ }^{2}+\frac{1}{2} m_{s} \dot{x}_{s}{ }^{2}+\frac{1}{2} m_{t} \dot{x}_{t}{ }^{2}
$$


Table 1. Parameters used in modeling of FDS.

\begin{tabular}{ll}
\hline Parameters used for modeling & Given value \\
\hline Screw mass $\left(m_{\mathrm{s}}\right)$ & $160 \mathrm{~kg}$ \\
Stone lifting platform mass $\left(m_{t}\right)$ & $750 \mathrm{~kg}$ \\
Axial stiffness of screw $\left(K_{s a}\right)$ & $8.4 \times 10^{7} \mathrm{~N} / \mathrm{m}$ \\
Axial stiffness of supporting & $2.3 \times 10^{8} \mathrm{~N} / \mathrm{m}$ \\
bearing $\left(K_{n a}\right)$ & \\
Motor rotation angle $\left(\theta_{m}\right)$ & State variable \\
Rotation angle of bevel gear $1\left(\theta_{g 1}\right)$ & State variable \\
Rotation angle of bevel gear $2\left(\theta_{g 2}\right)$ & State variable \\
Angle of rotation of nut $\left(\theta_{n}\right)$ & State variable \\
Axial displacement of nut $\left(x_{n}\right)$ & State variable \\
Axial displacement of screw $\left(x_{s}\right)$ & State variable \\
Axial displacement of the stone & State variable \\
lifting platform $\left(x_{t}\right)$ & \\
Nut mass $\left(m_{n}\right)$ & $15 \mathrm{~kg}$ \\
Inertia of nut $\left(J_{n}\right)$ & $1.8 \times 10^{-1} \mathrm{~kg} \cdot \mathrm{m}^{2}$ \\
Inertia of bevel gear $1\left(J g_{1}\right)$ & $6.67 \times 10^{-4} \mathrm{~kg} \cdot \mathrm{m}^{2}$ \\
Inertia of bevel gear $2\left(J g_{2}\right)$ & $5.54 \times 10^{-3} \mathrm{~kg} \cdot \mathrm{m}^{2}$ \\
Inertia of motor $\left(J_{m}\right)$ & $1.67 \times 10^{-1} \mathrm{~kg} \cdot \mathrm{m}^{2}$ \\
Meshing stiffness of gears $\left(K_{12}\right)$ & $6.2 \times 10^{8} \mathrm{~N} / \mathrm{m}$ \\
The synthesis torsional rigidity & $5.83 \times 10^{8} \mathrm{~N} / \mathrm{m}$ \\
of coupling and bevel gear shaft $\left(K_{g n}\right)$ & $5.8 \times 10^{8} \mathrm{~N} / \mathrm{m}$ \\
The synthesis torsional rigidity & \\
of nut and gear $2\left(K_{2 n}\right)$ & 3.18 \\
The transmission ratio & \\
of the nut screw $\left(i_{R}\right)$ & \\
\hline
\end{tabular}

Based on the motion relationship of screw, $x_{s}$ can be written as

$$
x_{s}=i_{R} \theta_{n}-x_{n}
$$

where $i_{R}$ is the transmission ratio, $i_{R}=p / 2 \pi$; and $p$ is the helical pitch, $p=10 \mathrm{~mm}$.

The potential energy of the FDS is as follows:

$$
\begin{aligned}
V & =\frac{1}{2} k_{g n}\left(\theta_{m}-\theta_{g 1}\right)^{2}+\frac{1}{2} k_{12}\left(\theta_{g 2}-\theta_{g 1}\right)^{2}+\frac{1}{2} k_{2 n}\left(\theta_{n}-\theta_{g 2}\right)^{2} \\
& +\frac{1}{2} k_{t a}\left(x_{t}-x_{s}\right)^{2}+\frac{1}{2} k_{n a} x_{n}{ }^{2}+\frac{1}{2} k_{s a} x_{s}{ }^{2}
\end{aligned}
$$

Let $L=T-V$, and

$$
\frac{d}{\mathrm{~d} t}\left(\frac{\partial L}{\partial \dot{q}_{j}}\right)-\frac{\partial L}{\partial q_{j}}=\mathbf{Q}_{\mathbf{j}}
$$

Generalized coordinates and generalized forces are given as follows:

$$
\begin{aligned}
& \mathbf{q}=\left(q_{1} q_{2} q_{3} q_{4} q_{5} q_{6}\right)^{T}=\left(\theta_{m} \theta_{g 1} \theta_{g 2} \theta_{n} x_{s} x_{t}\right)^{T} \\
& \mathbf{Q}=\left(Q_{1} Q_{2} Q_{3} Q_{4} Q_{5} Q_{6}\right)^{T}=\left(T_{m} 00000 F_{a}\right)^{T}
\end{aligned}
$$

where $T_{m}$ is the output torque of motor, $\mathbf{q}$ represents a six degree of freedom model, $F_{a}$ is the vertical load of cutting stone.

The dynamic equation of FDS can be described as the matrix form [19]

$$
\mathbf{M} \ddot{\mathbf{q}}+\mathbf{K q}=\mathbf{Q}
$$

where $\mathbf{M}$ and $\mathbf{K}$ are the mass and stiffness matrix of FDS. So as to simplify the analysis, the damping is not considered.

See equation (15) and (16) below.

where $\mathbf{M}$ and $\mathbf{K}$ are $6 \times 6$ square matrices, respectively.

$$
\mathbf{M}=\left[\begin{array}{cccccc}
J_{m}+J_{g 1} / 4 & J_{g 1} / 4 & 0 & 0 & 0 & 0 \\
J_{g 1} / 4 & J_{g 1}+J_{g 2} / 4 & J_{g 2} / 4 & 0 & 0 & 0 \\
0 & J_{g 2} / 4 & J_{g 2}+J_{n} / 4 & J_{n} / 4 & 0 & 0 \\
0 & 0 & J_{n} / 4 & i_{R}{ }^{2} m_{n}+J_{n} / 4 & -m_{n} i_{R} & 0 \\
0 & 0 & 0 & -m_{n} i_{R} & m_{n}+m_{s} & 0 \\
0 & 0 & 0 & 0 & 0 & m_{t}
\end{array}\right]
$$

$$
\mathbf{K}=\left[\begin{array}{cccccc}
k_{g n} & -k_{g n} & 0 & 0 & 0 & 0 \\
-k_{g n} & k_{g n}+k_{12} & -k_{12} & 0 & 0 & 0 \\
0 & -k_{12} & k_{12}+k_{2 n} & -k_{2 n} & 0 & 0 \\
0 & 0 & -k_{2 n} & k_{2 n}+i_{R}{ }^{2} k_{n a} & -i_{R} k_{n a} & 0 \\
0 & 0 & 0 & -i_{R} k_{n a} & k_{t a}+k_{s a}+k_{n a} & -k_{t a} \\
0 & 0 & 0 & 0 & -k_{t a} & k_{t a}
\end{array}\right]
$$




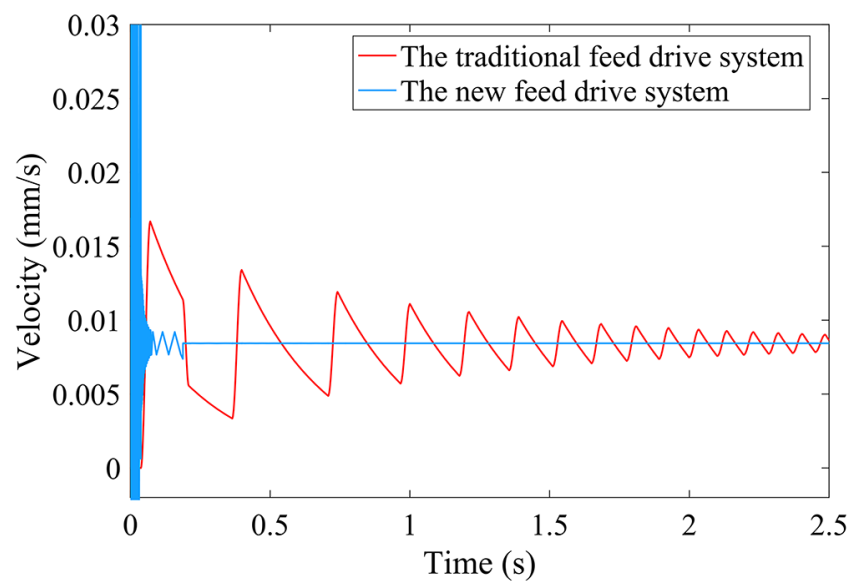

Fig. 4. Comparison of the velocity fluctuation between traditional and new FDS.

Equation (14) is expressed in state-space as follows

$$
\left\{\begin{array}{l}
\dot{X}=A X+B U \\
Y=C X
\end{array}\right.
$$

where $U$ is the state vector, $X$ is the input variable and $Y$ is the output variable. $A, B$ and $\mathrm{C}$ are the state, input and output matrix, respectively. They can be described as $\mathbf{X}=\left[\begin{array}{ll}\mathbf{q} & \dot{\mathbf{q}}\end{array}\right], \mathbf{A}=\left[\begin{array}{cc}\mathbf{0} & \mathbf{I} \\ -\mathbf{M}^{-1} \mathbf{K} & \mathbf{0}\end{array}\right], \mathbf{B}=\left[\begin{array}{c}\mathbf{0} \\ \mathbf{M}^{-1} \mathbf{Q}\end{array}\right]$, output variable $\mathbf{C}$.

\section{Simulation results and discussion}

\subsection{Comparison of the velocity fluctuation between traditional and new FDS}

Compared with the traditional FDS, the new FDS contains high stiffness components. The servo motor was used as the power source to realize the speed loop semi-closed loop control and the feed speed was stable. As shown in Figure 4, the velocity characteristics of FDS was simulated by Simulink-simscape. The results showed that the new FDS has a faster response feed and less velocity fluctuation.

\subsection{Analysis of frequency response characteristics of FDS}

Frequency characteristics of the stone lifting platform at the starting position, as shown in Figure 5a. The first twoorder natural frequency values $\left(f_{1}=42.81 \mathrm{~Hz}, f_{2}=227.1 \mathrm{~Hz}\right)$ that we can obtain according to the Table 1 . Figures $5 \mathrm{~b}$ and $5 \mathrm{c}$ show the frequency responses of the stone lifting platform at 0.25 and 0.5 of the screw length, respectively. As a result, the first two-order natural frequency of FDS has been obtained as follows: (b) $f_{1}=47.43 \mathrm{~Hz}, f_{2}=234.3 \mathrm{~Hz}$; (c) $f_{1}=54.91 \mathrm{~Hz}$, $f_{2}=249.9 \mathrm{~Hz}$. The traditional way is that the two ends of the

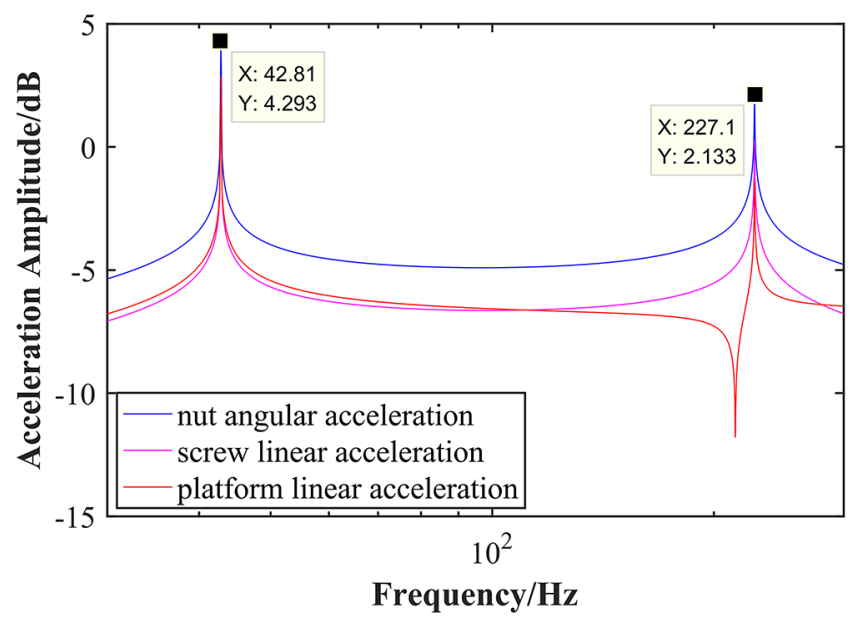

(a)

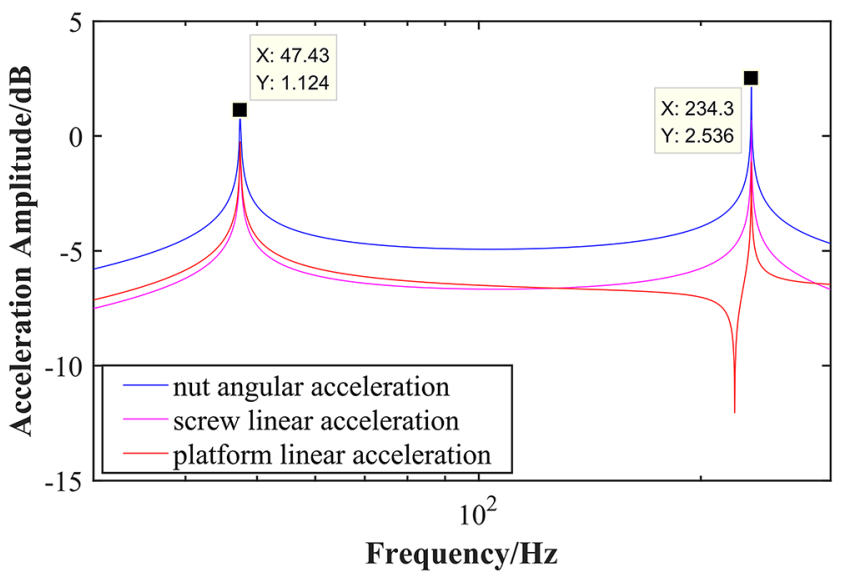

(b)

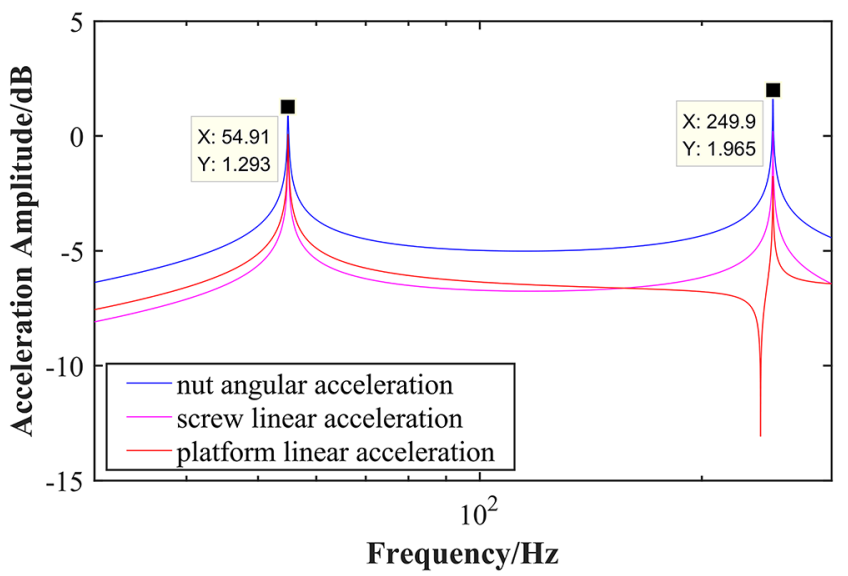

(c)

Fig. 5. Frequency responses of FDS (a) starting position (b) 0.25 of screw length (c) 0.5 of screw length.

screw are fixed, the table moves vertically. Therefore, the stiffness of the middle position of the screw is lower than that of the two ends. However, the distance between the free end and the fixed end is gradually reduced with the vertical movement of the stone lifting platform compared novel feed drive system 


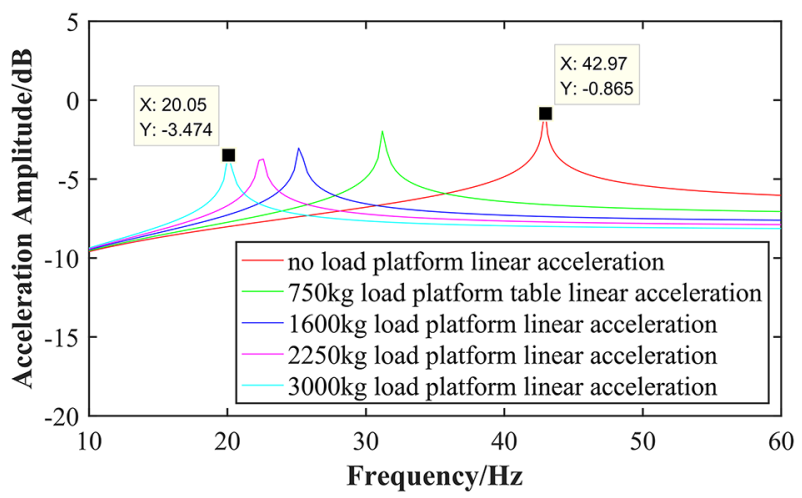

(a)

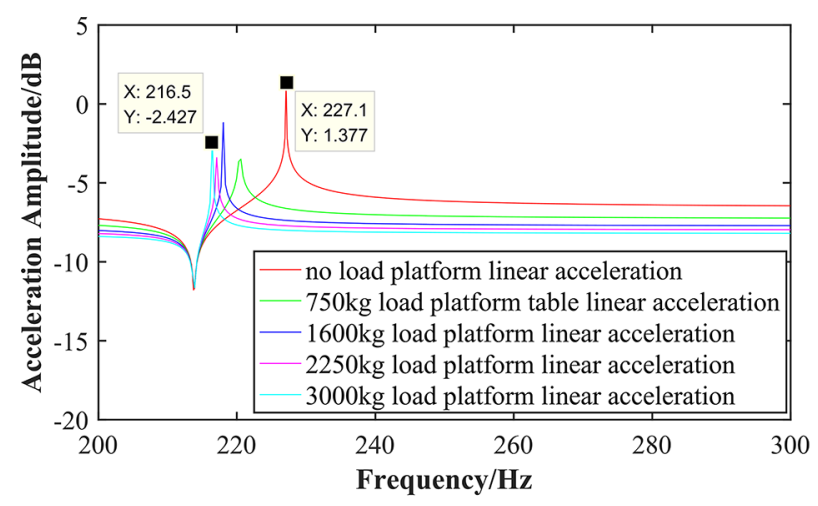

(b)

Fig. 6. Effect of workpiece mass on natural frequency (a) first-order (b) second-order.

with the traditional driving system. According to equation (1), $L$ is reduction leads to the axial stiffness of the trapezoidal screw is increasing.

\subsection{Influence of the mass of stone on the frequency characteristics of FDS}

Fixtures are often used to fasten the workpiece, however, the stone is fixed onto the stone lifting platform with cement which shift the mass of the platform in simulation. In order to calculate the influence of the mass of stone on the frequency response of FDS, the stiffness of the connection between the stone and the stone lifting platform was ignored. Further, the model is simplified, $M_{t}$ is defined as follows

$$
M_{t}=m_{t}+m_{L}
$$

where $m_{L}$ is the mass of stone, $m_{t}$ is the mass of stone lifting platform.

In addition, different workpieces mass affect the frequency response characteristics of FDS. In practical production, different mass of stone will be processed. Therefore, the natural frequency of the FDS at the starting position was investigated. The mass of stone has been changed as 3000, 4000, 5000 and $6000 \mathrm{~kg}$ to analyze the effect of mass on the natural frequency values for FDS. Figure 6 shows the effect of the frequency response function curve of the stone lifting platform's total mass variation, when the platform is at the starting position. The first order natural frequency shifts from the 20.05 to $14.96 \mathrm{~Hz}$ when the mass of stone increased from 3000 to $6000 \mathrm{~kg}$, as shown in Figure 6a. As shown in Figure 6b, the influence of mass on the second-order natural frequency range $(216.5-215.2 \mathrm{~Hz})$ is lower than that on the first-order natural frequency range (14.96-20.05 Hz). The acceleration amplitude of FDS is shown in Figure 6. Further, the acceleration amplitude of FDS is large when processing light weight stone. Thus, FDS has higher acceleration and response performance when processing light mass of stone.

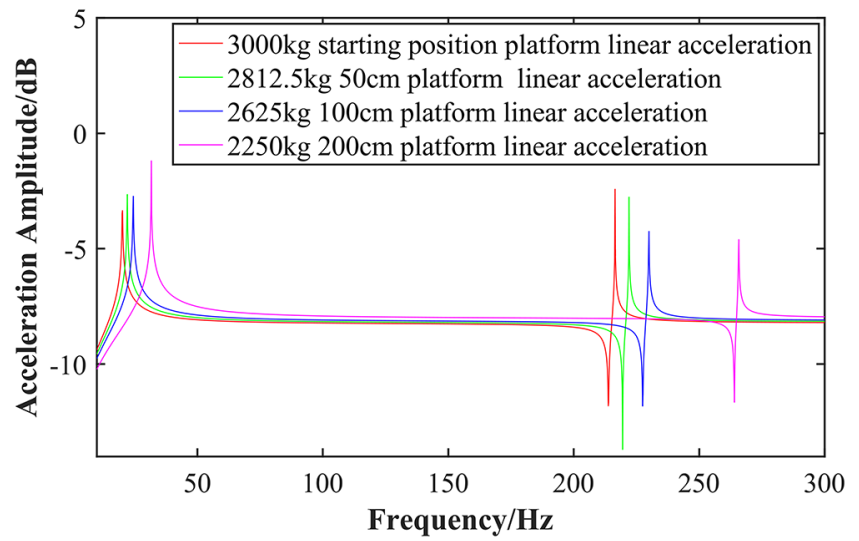

Fig. 7. Frequency responses of FDS vs position and mass.

\subsection{Influence of the mass and position of the stone in time-varying on the feed drive system's frequency response characteristics}

Rock is a kind of hard and brittle material. For a practical production state, stone is processed into large slabs while $25 \%$ of the stone can be converted into stone debris, which is removed with the cooling liquid. So the mass of the stone is changed with the displacement of the feed system during the processing. According to equation (1), the axial stiffness of screw is varying with the height of stone lifting platform. Therefore, the frequency response of FDS is timevarying with the mass and position of stone.

In this paper, a block of rock (length $2 \mathrm{~m}$, width $1 \mathrm{~m}$, height $2 \mathrm{~m}$ ) as example has been discussed. Consequently, the mass of stone and axial stiffness of screw was calculated for each $5 \mathrm{~cm}$ of FDS movement. In addition, the frequency response characteristic curve was obtained through simulation calculation as shown in Figure 7. Figure 8a shows the trend of the first-order frequency with timevarying with the mass and position of stone. It is observed that the natural frequency from 20.05 to $31.51 \mathrm{~Hz}$, and six adjacent measuring points were the same among them. 


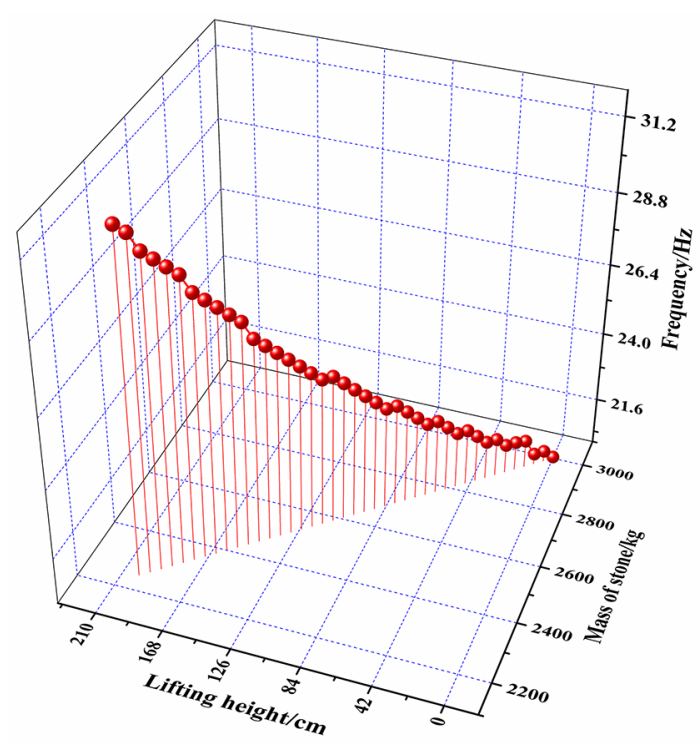

(a)

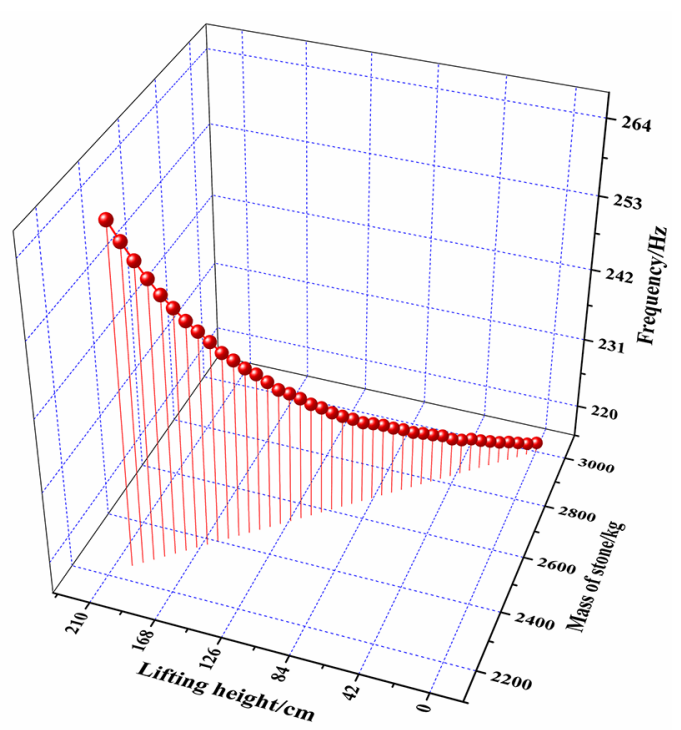

(b)

Fig. 8. Frequency shifts as stone mass and position varies (a) first-order (b) second-order.

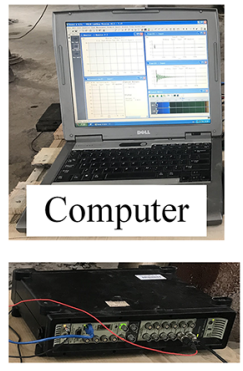

LMS Test.lab

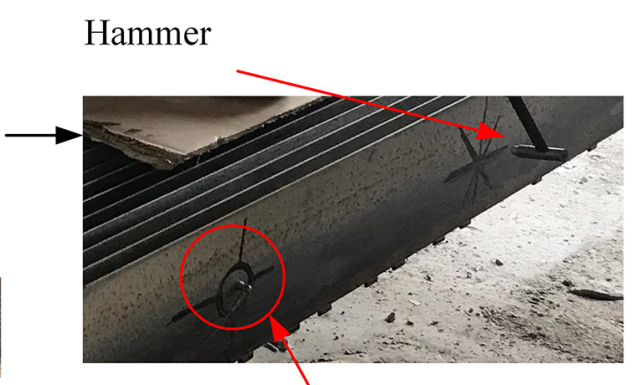

Acceleration sensor

Fig. 9. Experimental measurement setup of the saw blade frequency.

Hence, the first-order frequency becomes an increasing tendency as a whole. Figure $8 \mathrm{~b}$ shows the trend of secondorder frequency which change from 216.5 to $265.8 \mathrm{~Hz}$. By comparing the range of first-order and second-order natural frequencies, it is concluded that the range of influence on the second-order frequency during processing is greater than the first-order frequency.

The saw blade, a large-span thin plate with diamond saw-teeth, is used as a tool for cutting stone. During the machining process, the saw blade is excited to produce lateral vibration, which leads to an increase the sawing gap. In view of the fact that large sawing gaps can lead to scrap of slab. As shown in Figure 9, the modal tests was carried out for tensioned saw blade. The experimental results $\left(f_{1}=22 \mathrm{~Hz}, f_{2}=44 \mathrm{~Hz}\right)$ are shown in Figure 10. The firstorder natural frequency was within the range of the natural frequency of FDS. Moreover, the second-order natural frequency was near its range, which may resonate with FDS, cause the instability of FDS, and increase the sawing gap.

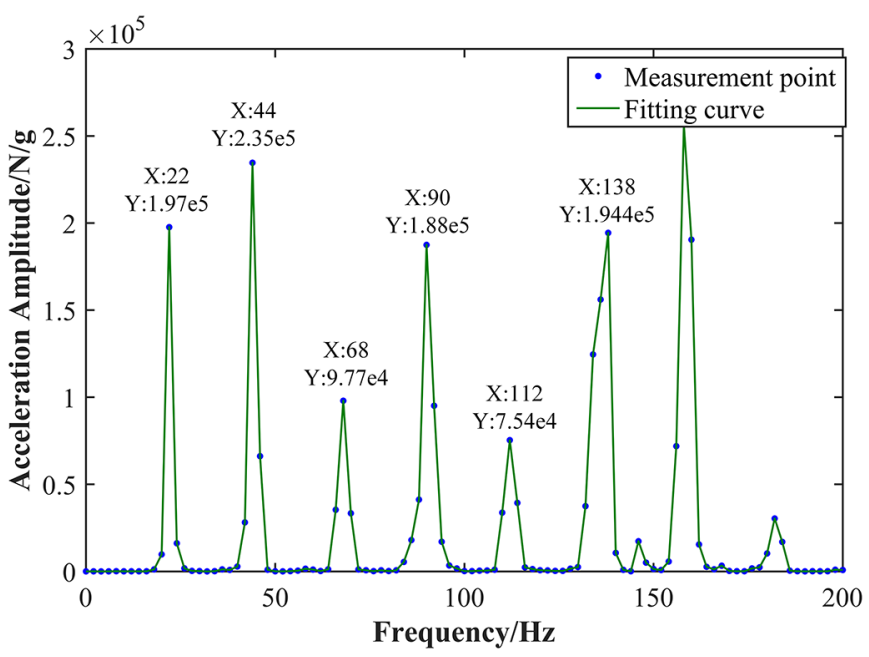

Fig. 10. Experimental results of the saw blade modal.

\section{Conclusion}

In this paper, dynamic model of frame saw machine's FDS was established based on the LPM. The dynamic characteristics of the FDS considering time-varying load has been studied. Several conclusions are as follows:

- The new FDS reduces the speed fluctuation and the maximum undeformed chip thickness. The maximum undeformed chip of materials in the cutting process is closer to the ideal state, thus reducing the wear of diamond.

- The natural frequency of the FDS varied nonlinearly with different mass of stone. At the starting position, the range of the first-order natural frequency of different mass of stones is larger than that of the second-order natural frequency. 
- The acceleration response of the FDS abates with the raise of the load. By analyzing the time-varying load, the first-order and second-order natural frequencies changed around $57.2 \%$ and $22.8 \%$, respectively. From the point of view of frequency range, however, the load has the greatest influence on second-order frequency.

- The first two natural frequencies of the saw blade are within the FDS frequency range, which will produce resonance phenomenon and affect the processing stability and product quality.

This work was supported by Provincial Key R\&D Program of Shandong Province (2019GGX104022).

\section{References}

[1] H. Zhang, J. Zhang, P. Dong, Q. Sun, Investigation of the sawing performance of a new type of diamond frame saw machine, Diam. Relat. Mat. 84, 11-19 (2018)

[2] H. Zhang, J. Zhang, S. Wang, Comparison of wear performance of diamond tools in frame sawing with different trajectories, Int. J. Refract. Met. Hard Mat. 78, 178-185 (2019)

[3] K.K. Varanasi, S.A. Nayfeh, The dynamics of lead-screw drives: low-order modeling and experiments, J. Dyn. Syst. Meas. Control-Trans. AMSE. 126, 388-396 (2004)

[4] Y. Altintas, A. Verl, C. Brecher, L. Uriarte, G. Pritschow, Machine tool feed drives, CIRP Ann-Manuf. Technol. 60, 779-796 (2011)

[5] S.G. Mu, Dynamic analysis of ball-screw with rotating nut driven, Comput. Model. New Technol. 18, 268-272 (2014)

[6] H. Yu, X. Feng, Dynamic modeling and spectrum analysis of macro-macro dual driven system, ASME J. Comput. Nonlinear Dyn. 11, 044505 (2016)

[7] Z. Wang, X. Feng, P. Li, F. Du, Dynamic modeling and analysis of the nut-direct drive system, Adv. Mech. Eng. 10, $1-11(2018)$

[8] W. Zhang, X. Zhang, J. Zhang, W. Zhao, Analysis of lead screw pre-stretching influences on the natural frequency of ball screw feed system, Precis. Eng. 57, 30-44 (2019)
[9] F. Li, Y. Jiang, T. Li, Y. Du, An improved dynamic model of preloaded ball screw drives considering torque transmission and its application to frequency analysis, Adv. Mech. Eng. 9, 1687814017710580 (2017)

[10] B. Henke, O. Sawodny, R. Neumann, Distributed parameter modeling of flexible ball screw drives using ritz series discretization, IEEE/ASME Trans. Mechatron. 20, 1226-1235 (2015)

[11] C.-H. Lee, M.-Y. Yang, C.-W. Oh, An integrated prediction model including the cutting process for virtual product development of machine tools, Int. J. Mach Tools Manuf. 9, 29-43 (2015)

[12] Z. Du, X.-L. Zhang, T. Tao, Study of the dynamic characteristics of ball screw with a load disturbance, Math. Probl. Eng. 2016, 8208241 (2016)

[13] S. Bai, T. Elwert, S. Jia, Q.Y. Wang, T. Liu, R. Yao, Methodologies for evaluating sawability of ornamental granite and relation modeling combining sawability with environmental impacts: an application in a stone industrial park of China, J. Clean Prod. 246, 119004 (2020)

[14] H. Zhang, J. Zhang, Z. Wang, Q. Sun, J. Fang, A new frame saw machine by diamond segmented blade for cutting granite, Diam. Relat. Mat. 69, 40-48 (2016)

[15] Q. Sun, J. Zhang, H. Zhang, P. Dong, Force and segment wear in various granites cutting by diamond frame saw, Proc. Inst. Mech. Eng. Part C-J. Eng. Mech. Eng. Sci. 232 3696-3707 (2017)

[16] J. Yuan, F. Scarpa, B. Titurus, G. Allegri, S. Patsias, R. Rajasekaran, Novel frame model for mistuning analysis of bladed disk systems, J. Vib. Acoust. Trans. ASME. 139, 0331016 (2017)

[17] M.B. Sanchez, M. Pleguezuelos, P.I. Jose, Influence of profile modifications on meshing stiffness, load sharing, and trasnsmission error of involute spur gears, Mech. Mach Theory 139, 506-525 (2019)

[18] S. Montgomery-Smith, W. Huang, A numerical method to model dynamic behavior of thin inextensible elastic rods in three dimensions, ASME J. Comput. Nonlinear Dyn. 9, 011015 (2014)

[19] M. Peasgood, E. Kubica, J. McPhee, Stabilization of a dynamic walking gait simulation, ASME J. Comput. Nonlinear Dyn. 2, 65-72 (2007)

Cite this article as: D. Sun, J. Zhang, Dynamics modeling and analysis of feed drive system for a frame saw machine considering time-varying load, Mechanics \& Industry 22, 26 (2021) 